\title{
Parametric experimental tests of steam gasification of pine wood in a fluidized bed reactor
}

\author{
L. Vecchione, ${ }^{1}$ M. Moneti, ${ }^{1}$ S. Cocchi, ${ }^{1}$ M. Villarini, ${ }^{1}$ M. Sisinni, ${ }^{2}$ A. Micangeli ${ }^{2}$ \\ ${ }^{1}$ DAFNE, Tuscia University, Viterbo, Italy; ${ }^{2}$ Dipartimento di Ingegneria Meccanica e Aerospaziale, \\ Sapienza University, Roma, Italy
}

\begin{abstract}
Among Renewable Energy Sources (RES), biomass represent one of the most common and suitable solution in order to contribute to the global energy supply and to reduce greenhouse gases (GHG) emissions. The disposal of some residual biomass, as pruning from pine trees, represent a problem for agricultural and agro-industrial sectors. But if the residual biomass are used for energy production can become a resource. The most suitable energy conversion technology for the above-mentioned biomass is gasification process because the high $\mathrm{C} / \mathrm{N}$ ratio and the low moisture content, obtained from the analysis. In this work a small-pilot bubbling-bed gasification plant has been designed, constructed and used in order to obtain, from the pine trees pruning, a syngas with low tar and char contents and high hydrogen content. The activities showed here are part of the activities carried out in the European 7FP UNIfHY project. In particular the aim of this work is to develop experimental test on a bench scale steam blown fluidized bed biomass gasifier. These tests will be utilized in future works for the simulations of a pilot scale steam fluidized bed gasifier (100 kWth) fed with different biomass feedstock. The results of the tests include produced gas and tar composition as well gas, tar and char yield. Tests on a bench scale reactor ( $8 \mathrm{~cm}$ I.D.) were carried out varying steam to biomass ratio from $0.5,0.7$ and 1 to $830^{\circ} \mathrm{C}$.
\end{abstract}

\section{Introduction}

Nowadays biomass represents an important renewable energy resource because they are present in various form sand species in all parts of the world. Their use allows to not increase the carbon bioxide concentration ${ }^{[1]}$, infact the carbon bioxide emissions quantity during their use is the same of the quantity that the biomass has absorbed

Correspondence: Luigi Vecchione, DAFNE, Tuscia University, Via San Camillo de Lellis, 01100 Viterbo, Italy

E-mail: l.vecchione@unitus.it

Key words: steam gasification, pine wood, Renewable Energy Sources

Copyright L. Vecchione et al., 2013

Licensee PAGEPress, Italy

Journal of Agricultural Engineering 2013;XLIV(s2):e116

doi:10.4081/jae.2013.s2.e116

This article is distributed under the terms of the Creative Commons Attribution Noncommercial License (by-nc 3.0) which permits any noncommercial use, distribution, and reproduction in any medium, provided the original author(s) and source are credited. from the atmosphere during the cycle life ${ }^{[1]}$.In this way biomass represents one of the most common and suitable solution in order to contribute to the global energy supply and to reduce greenhouse gases (GHG) emissions. Another important feature is represented by a major economic independence from fossil fuels increasing in this way the economy and the development of the agriculture sector of the territory. The disposal of some residual biomass, as p runing from pine trees, represent a problem for agricultural and agro-industrial sectors. But if the residual biomass are used for energy production can become a resource. One of the promising technologies which utilizes the biomass wastes is biomass gasification. The gasification of lignocellulosic biomass is one of the most thermo-chemical conversions technologies developed because it offers high con version efficiency ${ }^{[2]}$. It is one of the strategies for exploitation of renewable fuels and power generation. Biomass gasification converts the biomass wastes into clean fuel gases and biofuels. There are two main categories of gasifier, fixed bed and fluidized bed The most suitable energy conversion technology for the above-mentioned biomass is gasification process ${ }^{[3]}{ }^{[4]}$ because the high $\mathrm{C} / \mathrm{N}$ ratio and the low moisture content, obtained from the analysis. The gasification plants are able to have a primary role in the world system because the electric production is constant and is not necessary any energy storage system, the emissions quantity is controlled, and the energy production is not subjected at aleatory events (as cloud cover or strong winds).

After the gasification process the biomass is transformed in syngas, composed by hydrogen, carbon monoxide, carbon dioxide and methane, with tar, and a solid residue as char and ash.

Furthermore, steam gasification, as the method chosen to gasify biomass in the present work, has other advantages because (i) it produces a gas with higher heating value, (ii) it reduces the diluting effect of N2 from air and (iii) eliminates the need for an expensive oxygen plant when both air and oxygen are used as gasification mediums ${ }^{[5]}$.

The product distribution varies with the biomass used and the gasification temperature. These differences for the $\mathrm{H} 2, \mathrm{CO}$ and $\mathrm{CO} 2$ contents in the gas product decrease when the temperature increases to $830^{\circ} \mathrm{C}$ at which point a gas composition similar for all types of biomass tested is obtained by the achievement of equilibrium in the water-gas shift reaction ${ }^{[6]}$. The proposed gasification was based on the following reactions:

$\begin{array}{ll}\mathrm{C}+\mathrm{H} 2 \mathrm{O} \rightarrow \mathrm{CO}+\mathrm{H} 2 & \mathrm{R} 1 \\ \mathrm{C}+\mathrm{CO} 2 \rightarrow 2 \mathrm{CO} & \mathrm{R} 2 \\ \mathrm{C}+2 \mathrm{H} 2 \rightarrow \mathrm{CH} 4 & \mathrm{R} 3 \\ \mathrm{CH} 4+\mathrm{H} 2 \mathrm{O} \leftrightarrow \mathrm{CO}+3 \mathrm{H} 2 & \mathrm{R} 4 \\ \mathrm{CO}+\mathrm{H} 20 \leftrightarrow \mathrm{CO} 2+\mathrm{H} 2 & \mathrm{R} 5\end{array}$

But one of the major problems encountered in gasification processes is the tar formation, which reduces the efficiency of gas production and interferes with the equipment operation. Various methods have been investigated to e liminate or reduce the tar formation ${ }^{[5,6]}$. Tar are defined as all organic contaminants with a molecular weight larger than benzene Tar removal technologies can broadly be divided into two approaches; hot gas cleaning after the gasifier and 
treatments inside the gasifier ${ }^{[2]}$. The different approaches of the second one are a proper selection of operating parameters, use of bed additive/catalyst, and gasifier modifications. The operating parameters such as temperature, gasifying agent, steam to biomass ratio, etc. play an important role in formation and decomposition of tar; using some active bed additives such as dolomite, olivine, char, etc. inside the gasifier can be facilitated the tar reforming. If the gasifier bed is well designed and operated, it can produce a very clean gas with respect to the end user application, eliminating the use of downstream secondary steps. In this work a small-pilot bubbling-bed gasification plant has been designed, constructed and used in order to obtain, from the pine trees pruning, a syngas with low tar and char contents and high hydrogen content. The activities showed here are part of the activities carried out in the European 7FP UNIfHY project. The UNIfHY project includes an innovative fluidized bed gasifier with catalytic filter in the freeoboard of the reactor allowing steam reforming process of tar with high temperature keepi ng high thermic efficiency; it allows to resolve the problem of the high pollutants emissions producing a syngas with high purity and rich of hydrogen. In particular the aim of this work is to develop experimental test on a bench scale steam blown fluidized bed biomass gasifier. These tests will be utilized in future works for the simulations of a pilot scale steam fluidized bed gasifier (100 kWth) fed with different biomass feedstock..

\section{Experimental facility}

The installation of the bench scale facility used in this work is shown in Figure 1.

Its major components are: a solid fuel feeding system, a fluidized bed gasifier, a gas cooling system, and metering and analyzing systems for the off-gases. The fluidized bed gasifier consists of an austenitic stainless steel cylindrical vessel of internal diameter 80 $\mathrm{mm}$ fitted with stainless steel porous distributor plate, designed to allow a good gas distribution at all temperatures. In particular a sintered stainless steel plate is used. The pressure drops through this plate are higher than $40 \%$ of those through the fluidized bed yet at ambient temperature, in order to guarantee a uniform gas distribution at every temperature. The entire reactor is located in a cylindrical electric furn ace provided with temperature and heating rate control systems. Temperature within the reactor is measured by means of two thermocouples, one immersed in the bed and the other located under the distributor. The bed inventory is olivine sand. Fluidized gas is a mix of steam and nitrogen: the flowrate of steam is set to obtain the desired steam to biomass ratio while nitrogen is added to guarantee a superficial velocity equal to two times of the minimum fluidization velocity. Water for the generation of steam is fed to an electrically heated boiler by means of a peristaltic pump at a constant flow rate. The biomass feeding system is designed to properly deliver the biomass inside the bubbling bed. During the start-up, the entire raw gas generated by biomass gasification feeds a torch to be completely burned. When gasification process reaches the steady state condition a heated ceramic filter assures that no fine particles .For each run the permanent gas yield was measured by means of a volumetric gasmeter, after separation of the condensate (water and organic phases) in a cold bath of isopropanol $\left(-10^{\circ} \mathrm{C}\right)$. The flow rate of the slipstream was controlled by a needle valve. The TAR was measured after each test by means of Agilent GC-MS. Gas products were analysed by Varian micro-GC.

\section{Process cescription and results}

Tests on a bench scale reactor ( $8 \mathrm{~cm}$ I.D.) were carried out varying

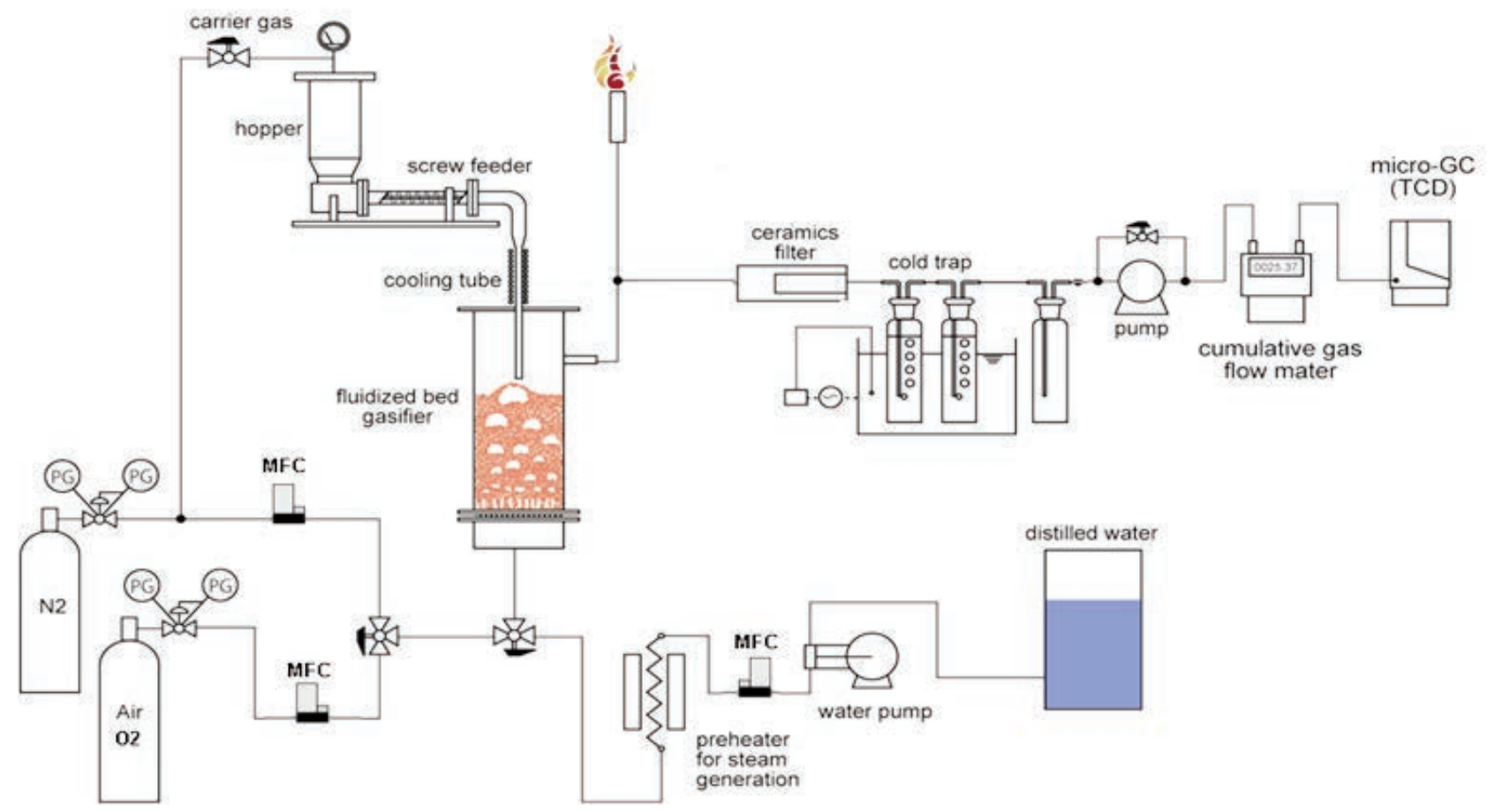

Figure 1. Experimental Facility 


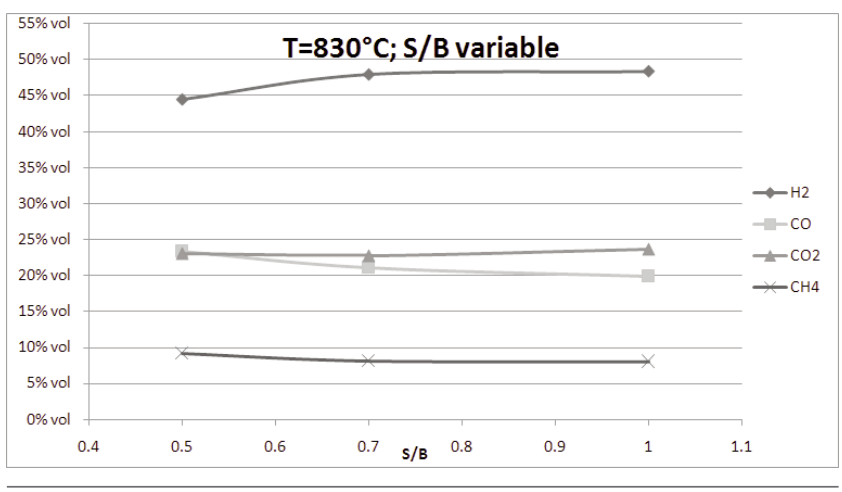

Figure 2. The effect of the steam/biomass ratio on the product distribution

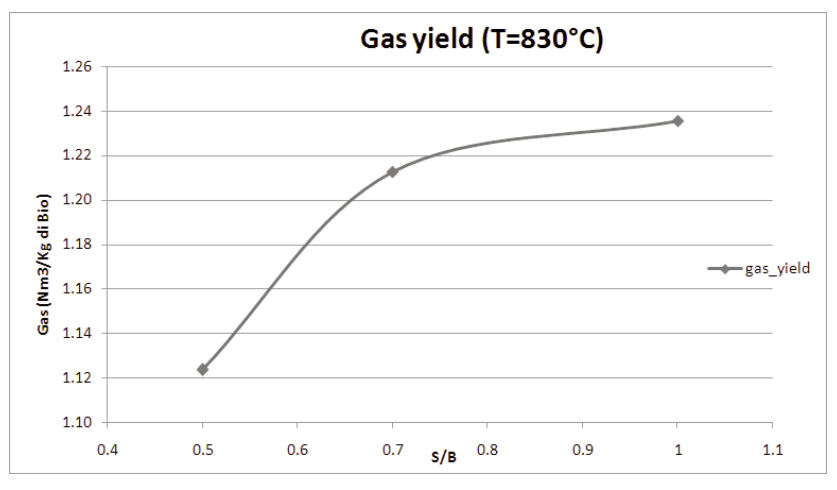

Figure 4. The effect of the steam/biomass ratio on the gas yield

Table 2. Operating test

\begin{tabular}{lc} 
Biomass Flow Rate $(\mathrm{g} / \mathrm{h})$ & 134 \\
\hline Operative Temperature $\left({ }^{\circ} \mathrm{C}\right)$ & 830 \\
Wind Box Temperature $\left({ }^{\circ} \mathrm{C}\right)$ & 450 \\
\hline Vaporize Temperature $\left({ }^{\circ} \mathrm{C}\right)$ & 200 \\
S/B & $0.5 ; 0.7 ; 1$ \\
\hline
\end{tabular}

steam to biomass ratio from $0.5,0.7$ to 1 fixing the temperature at 830 ${ }^{\circ} \mathrm{C}$. The results of the tests include produced gas and tar composition as well gas, tar and char yield, the wood-gas LHV and process efficiency. Below a preliminary biomass analysis is reported in Table 1, together with average particle size and density.

The main operation parameters are shown in Table 2. The variables studied have been the gasification temperature, and steam/biomass ratio. During tests the temperature was set at $830^{\circ} \mathrm{C}$, to assess the effects of the steam to biomass ratio variation and to evaluate the best operative conditions in order to produce high quantity of hydrogen and low tar and char content.

The conversion of char increases with the $\mathrm{S} / \mathrm{B}$ ratio, as can be seen from Figure 3 . Residual char was varied between 0.11 and $0.08 \mathrm{~g} / \mathrm{gbio}$, therefore increases the rate of gas flow product (this is due to an increase in steam). By the formula R1 it is observed that this also increases the production of hydrogen. Instead for the R5 consumption $\mathrm{CO}$ which then decreases, as seen from table 3 . The $\mathrm{CH} 4$ decreases for the reforming $\mathrm{R} 4$. The $\mathrm{C} 02$, on the other hand, remains constant because of balance of R5 and R2.

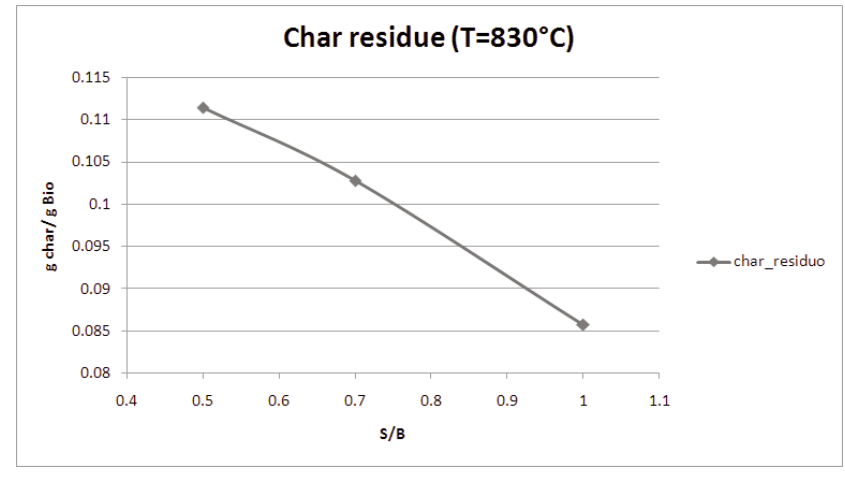

Figure 3. The effect of the steam/biomass ratio on the char residue

Table 1. Biomass Analysis

\begin{tabular}{lc} 
Type & Black Pine wood \\
Status & Raw \\
Moisture (wt \%) & 11 \\
\hline Ash (wt \%) & 0.5 \\
Carbon (wt \%) & 49,1 \\
\hline Hydrogen (wt \%) & 6.36 \\
Oxygen (wt \%) & 44.3 \\
\hline Particle size (mm) & $1-2$ \\
Particle Density (kg/m3) & 510 \\
\hline
\end{tabular}

Table 3. Results of the tests at different $\mathrm{S} / \mathrm{B}$ ratios.

\begin{tabular}{lcccccc}
\multicolumn{7}{c}{$\mathrm{T}=830^{\circ} \mathrm{C}$} \\
\hline S/B & Char (g/gbio) & Gas (Nm3/kg bio) & $\mathrm{H} 2(\%)$ & $\mathrm{CO}(\%)$ & $\mathrm{CO} 2(\%)$ & $\mathrm{CH} 4(\%)$ \\
\hline 0,5 & 0,111439162 & 1,12 & 0,444323 & 0,233874 & 0,230027 & 0,091777 \\
0,7 & 0,102801161 & 1,21 & 0,479298 & 0,21113 & 0,228083 & 0,081488 \\
1 & 0,085758049 & 1,24 & 0,48372 & 0,199323 & 0,236447 & 0,080509 \\
\hline
\end{tabular}

In the table below the effect of steam/biomass ratio on the analysed TARs (Benzene, Xylene, Styrene, Toluene, Naphtalene) is shown.

At this temperature varying the steam to biomass ratio, the total amount of TARs (for Nm3 of syngas) remains practically unchanged.

\section{Bibliography}

1. Orecchini, F., Bocci, E.: Biomass to hydrogen for the realization of closed cycles of energy resources. Energy. 32, 1006-1011 (2007).

2. Devi, L., Ptasinski, K.J., Janssen, F.J.: A review of the primary measures for tar elimination in biomass gasification processes. Biomass and Bioenergy. 24, 125-140 (2003).

3. Wang, L., Weller, C.L., Jones, D.D., Hanna, M.A.: Contemporary issues in thermal gasification of biomass and its application to electricity and fuel production. Biomass and Bioenergy. 32, 573581 (2008). 
4. $\quad$ Alauddin, Z.A.B.Z., Lahijani, P., Mohammadi, M., Mohamed, A.R.: Gasification of lignocellulosic biomass in fluidized beds for renewable energy development: A review. Renewable and Sustainable Energy Reviews. 14, 2852-2862 (2010).

5. Franco, C., Pinto, F., Gulyurtlu, I., Cabrita, I.: The study of reactions influencing the biomass steam gasification process $\hbar^{2}$. Fuel. 82, 835-842 (2003).

6. Herguido, J., Corella, J., Gonzalez-Saiz, J.: Steam gasification of lignocellulosic residues in a fluidized bed at a small pilot scale. Effect of the type of feedstock. Industrial \& engineering chemistry research. 31, 1274-1282 (1992).

7. Turn, S., Kinoshita, C., Zhang, Z., Ishimura, D., Zhou, J.: An experimental investigation of hydrogen production from biomass gasification. International Journal of Hydrogen Energy. 23, 641-648 (1998). 